\title{
Correction to: Best MRI sequences for identifying axillary lymph node markers in patients with metastatic breast cancer: an inter-reader observational study
}

Naziya Samreen ${ }^{1}$, Asha A. Bhatt ${ }^{2 *}$, Kalie Adler ${ }^{3}$, Shannon Zingula ${ }^{2}$ and Katrina N. Glazebrook ${ }^{2}$

\author{
Correction to: Eur Radiol Exp 4, 34 (2020) \\ https://doi.org/10.1186/s41747-020-00161-6
}

The original article [1] contains an error in the second paragraph of the Methods section regarding the description of the composition of a Tumark marker.

The original article states:

"A Tumark marker consists of two parts: a metallic core made of titanium or stainless steel and a bioabsorbable suture-like netting that surrounds the metal..."

This statement should be disregarded in favour of the following statement:

"A Tumark marker is made of non-resorbing nitinol that expands into a distinct shape upon deployment..."

\section{Author details}

${ }^{1}$ NYU Langone, 765 Stewart Ave, Garden City, NY 11530, USA. ²Department of Radiology, Mayo Clinic, 2001 st street SW, Rochester, MN 55905, USA. ${ }^{3}$ St. Vincent Healthcare, 2900 12th Ave N, Billings, MT 59101, USA.

Published online: 18 August 2020

\section{Reference}

1. Samreen N, Bhatt AA, Adler K, Zingula S, Glazebrook KN (2020) Best MRI sequences for identifying axillary lymph node markers in patients with metastatic breast cancer: an inter-reader observational study. Eur Radiol Exp 4:34. https://doi.org/10.1186/s41747-020-00161-6

\footnotetext{
The original article can be found online at https://doi.org/10.1186/s41747020-00161-6.

* Correspondence: bhatt.asha@mayo.edu

${ }^{2}$ Department of Radiology, Mayo Clinic, 200 1st street SW, Rochester, MN

55905, USA

Full list of author information is available at the end of the article
}

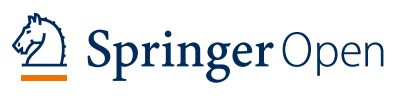

(c) The Author(s). 2020 Open Access This article is licensed under a Creative Commons Attribution 4.0 International License which permits use, sharing, adaptation, distribution and reproduction in any medium or format, as long as you give appropriate credit to the original author(s) and the source, provide a link to the Creative Commons licence, and indicate if changes were made. The images or other third party material in this article are included in the article's Creative Commons licence, unless indicated otherwise in a credit line to the material. If material is not included in the article's Creative Commons licence and your intended use is not permitted by statutory regulation or exceeds the permitted use, you will need to obtain permission directly from the copyright holder. To view a copy of this licence, visit http://creativecommons.org/licenses/by/4.0/. 